Keywords: dichloroacetate; hyperpolarised ${ }^{13} \mathrm{C}-\mathrm{MRS} ;{ }^{1} \mathrm{H}-\mathrm{MRS}$; autophagy; monocarboxylate transporter-1 inhibitor; $\left[1-{ }^{13} \mathrm{C}\right]$ pyruvate; pyruvate to lactate exchange rate

\title{
Dichloroacetate induces autophagy in colorectal cancer cells and tumours
}

\author{
G Lin ${ }^{1,2,6}$, D K Hill ${ }^{1,6,7}$, G Andrejeva ${ }^{1}$, J K R Boult ${ }^{1}$, H Troy ${ }^{1,8}$, A-C L F W T Fong ${ }^{1}$, M R Orton ${ }^{1}$, R Panek ${ }^{1}$,
} H G Parkes ${ }^{1}$, M Jafar ${ }^{1}$, D-M Koh ${ }^{1}$, S P Robinson ${ }^{1}$, I R Judson ${ }^{3}$, J R Griffiths ${ }^{4}$, M O Leach ${ }^{*}$, , T R Eykyn ${ }^{1,5}$ and Y-L Chung ${ }^{\star}, 1$

\begin{abstract}
${ }^{1}$ Cancer Research UK Cancer Imaging Centre, Division of Radiotherapy and Imaging, The Institute of Cancer Research London and Royal Marsden Hospital, Sutton, Surrey SM2 5PT, UK; ${ }^{2}$ Department of Medical Imaging and Intervention, Chang Gung Memorial Hospital at Linkou, College of Medicine, Chang Gung University, Taoyuan 333, Taiwan; ${ }^{3}$ Cancer Research UK Cancer Therapeutics Unit, The Institute of Cancer Research London, Sutton, Surrey SM2 5NG, UK; ${ }^{4} C R-U K$ Cambridge Institute, Li Ka Shing Centre, Cambridge CB2 ORE, UK and ${ }^{5}$ Division of Imaging Sciences and Biomedical Engineering, Kings College London, The Rayne Institute, St Thomas Hospital, London SE1 7EH, UK
\end{abstract}

Background: Dichloroacetate (DCA) has been found to have antitumour properties.

Methods: We investigated the cellular and metabolic responses to DCA treatment and recovery in human colorectal (HT29, HCT116 WT and HCT116 Bax-ko), prostate carcinoma cells (PC3) and HT29 xenografts by flow cytometry, western blotting, electron microscopy, ${ }^{1} \mathrm{H}$ and hyperpolarised ${ }^{13} \mathrm{C}$-magnetic resonance spectroscopy.

Results: Increased expression of the autophagy markers LC3B II was observed following DCA treatment both in vitro and in vivo. We observed increased production of reactive oxygen species (ROS) and mTOR inhibition (decreased pS6 ribosomal protein and p4E-BP1 expression) as well as increased expression of MCT1 following DCA treatment. Steady-state lactate excretion and the apparent hyperpolarised $\left[1-{ }^{13} \mathrm{C}\right]$ pyruvate-to-lactate exchange rate $\left(k_{\mathrm{PL}}\right)$ were decreased in DCA-treated cells, along with increased $\mathrm{NAD}^{+} / \mathrm{NADH}$ ratios and $\mathrm{NAD}^{+}$. Steady-state lactate excretion and $k_{\mathrm{PL}}$ returned to, or exceeded, control levels in cells recovered from DCA treatment, accompanied by increased $\mathrm{NAD}^{+}$and NADH. Reduced $k_{\mathrm{PL}}$ with DCA treatment was found in HT29 tumour xenografts in vivo.

Conclusions: DCA induces autophagy in cancer cells accompanied by ROS production and mTOR inhibition, reduced lactate excretion, reduced $k_{P L}$ and increased $\mathrm{NAD}^{+} / \mathrm{NADH}$ ratio. The observed cellular and metabolic changes recover on cessation of treatment.

Dichloroacetate (DCA) is a pyruvate dehydrogenase kinase (PDK) inhibitor, which activates pyruvate dehydrogenase $(\mathrm{PDH})$, and increases glucose oxidation by promoting influx of pyruvate into the Krebs cycle. DCA has been shown to cause production of reactive oxygen species (ROS) (Bonnet et al, 2007). It has been found to have anti-tumour properties by inducing cell-cycle arrest and apoptosis in small-cell lung (Bonnet et al, 2007), prostate
(Cao et al, 2008), colorectal (Madhok et al, 2010), breast (Sun et al, 2010), T-cell lymphoma (Kumar et al, 2012) and head and neck squamous cell (Sun et al, 2009) carcinoma models. Additive antitumour effects were found in the recently published DCA combination studies, for example, DCA in combination with radiation in prostate cancer (Cao et al, 2008), arsenic trioxide in breast cancer (Sun et al, 2011), platinum-based drugs (Fiebiger et al, 2011) or sulindac

\footnotetext{
*Correspondence: Professor MO Leach; E-mail: martin.leach@icr.ac.uk or Dr Y-L Chung; E-mail: ylichung@icr.ac.uk

${ }^{6}$ These authors contributed equally to this work.

${ }^{7}$ Current address: Department of Circulation and Medical Imaging, Norwegian University of Science and Technology, Trondheim 7491, Norway.

${ }^{8}$ Current address: Abbott Ireland Diagnostics Division, Pregnancy and Fertility Team, Lisnamuck, Longford, Ireland.
}

Received 11 March 2014; revised 22 April 2014; accepted 30 April 2014;

published online 3 June 2014

(c) 2014 Cancer Research UK. All rights reserved 0007-0920/14

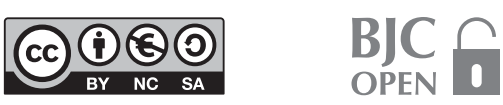


(Ayyanathan et al, 2012) in lung cancer, 5-flurouracil in colorectal cancer (Tong et al, 2011), bortezomib in multiple myeloma (Sanchez et al, 2013), sorafenib in hepatic carcinoma (Shen et al, 2013) and bevacizumab in glioblastoma (Kumar et al, 2013). DCA is currently in clinical trial (http://clinicaltrials.gov/show/ NCT01111097; Michelakis et al, 2010).

Magnetic resonance spectroscopy (MRS) is widely used to measure metabolite concentrations in cell extracts, whole cells, tissue biopsies and in vivo (Chung and Griffiths, 2007, 2011). Advances in hyperpolarised ${ }^{13} \mathrm{C}$-MRS using dynamic nuclear polarisation (DNP) have further enabled real-time measurements of the kinetics of a range of important endogenous enzymes (Golman et al, 2006a,b), such as lactate dehydrogenase (LDH), either in vitro in suspensions of viable whole cells or in tumours in vivo (Ward et al, 2010). Previous studies using hyperpolarised ${ }^{13} \mathrm{C}$-MRS have shown significant decreases in lactate-to-bicarbonate ratio (Park et al, 2013) and pyruvate-to-lactate exchange (Seth et al, 2011) in tumour models following 24-h treatment with DCA. Apparent pyruvate-to-lactate exchange rate constants $\left(k_{\mathrm{PL}}\right)$ have been shown to decrease following drug-induced depletion of the cofactors $\mathrm{NAD}(\mathrm{H})$ (Day et al, 2007) and have been shown to be dependent on NAD + /NADH ratios (Christensen et al, 2014) and the expression and activity of LDH (Ward et al, 2010) as well as on the activity of members of the monocarboxylate transporter family (MCTs), which mediate pyruvate and lactate transport into and out of the cell (Harris et al, 2009).

Cells with impaired apoptosis pathways may be resistant to DCA. In this study, we investigate potential non-invasive biomarkers of response following DCA treatment and during recovery from treatment, evaluating the cellular and metabolic effects of DCA on cancer cells that are able to undergo apoptosis (HCT116 wild-type (WT) and HT29 colorectal carcinoma cells, PC3 prostate carcinoma cells) and a cancer cell line that lacks this ability (HCT116 Bax-ko cells that are deficient in the protein Bax; Zhang et al, 2000).

Surprisingly, we observed minimal apoptosis or necrosis in all the cell lines but instead observed induction of autophagy and increased expression of LC3B II in all the cell lines following $24 \mathrm{~h}$ of DCA treatment. Induction of autophagy was also found in DCA-treated HT29 xenografts. We observed increased ROS production and mTOR inhibition (as demonstrated by the reduction in the phosphorylation of S6 ribosomal protein and $4 \mathrm{E}-\mathrm{BP} 1$ ), suggesting that they have a role in the induction of autophagy following DCA treatment in these cell lines.

The measured lactate excretion into the culture media was reduced after DCA treatment, returned to control levels following recovery in HCT116 Bax-ko cells and exceeded control levels in recovered HCT116 WT cells. Significant reductions in the apparent forward rate constant $k_{\mathrm{PL}}$ (and associated increased $\mathrm{NAD}^{+} /$ $\mathrm{NADH}$ ratios and $\mathrm{NAD}^{+}$levels in cells) were observed following DCA treatment in all the cell lines as well as in HT29 xenografts. Significantly higher $k_{\mathrm{PL}}, \mathrm{NADH}$ and $\mathrm{NAD}^{+}$levels were found following 48-h recovery from DCA treatment in HCT116 Bax-ko cells when compared with controls. Our data indicated that DCA-induced autophagy is a reversible process with recovery of cell growth as well as a recovery in metabolism when treatment is stopped.

\section{MATERIALS AND METHODS}

Cells and cell culture. All media and reagents for cell culture were purchased from Invitrogen (Paisley, UK). HT29, PC3 and HCT116 WT cells were purchased from American Type Culture Collection (ATCC, Manassas, VA, USA), and HCT116 Bax-ko cells were a kind gift from Dr. Bert Vogelstein, Johns Hopkins Medical Center,
USA; via Dr. Paul Clarke, ICR, Sutton, UK (Zhang et al, 2000). PC3, HCT116 Bax-ko and WT cells were cultivated in Dulbecco's Modified Eagle Medium with glutamine and non-essential amino acids. HT29 cells were cultivated in McCoy 5A medium with glutamine and HEPES. All culture media were supplemented with penicillin-streptomycin and $10 \%$ fetal bovine serum. Cells were cultivated in an incubator at $37^{\circ} \mathrm{C}$ in a humidified atmosphere containing $95 \%$ air and $5 \% \mathrm{CO}_{2}$. Cells were tested every month to ensure that they were free from mycoplasma infection.

Cell treatment. HCT116 Bax-ko and HCT116 WT cells were treated with $30 \mathrm{ng} \mathrm{ml}^{-1}$ tumour necrosis factor-related apoptosisinducing ligand/Apo 2L (TRAIL, PeproTech EC 310-04, Rocky Hill, NJ, USA) for $24 \mathrm{~h}$ to confirm the impaired apoptosis pathway in HCT116 Bax-ko cells (Han et al, 2008). HT29, PC3 and HCT116 Bax-ko and HCT116 WT cells were treated with $100 \mathrm{~mm}, \quad 80 \mathrm{~mm}, \quad 75 \mathrm{~mm}$ and $75 \mathrm{~mm}$ DCA (Sigma-Aldrich, Gillingham, UK), respectively, for $24 \mathrm{~h}$, to achieve approximately $40 \%$ of adherent cells relative to controls. For the cellular and metabolic analysis of cells recovered from autophagy, HCT116 WT and HCT116 Bax-ko cells were treated with DCA for $24 \mathrm{~h}$ and were then recovered for a further $48 \mathrm{~h}$ in normal DMEM culture medium (with glutamine, non-essential amino acids, $10 \%$ fetal calf serum and penicillin/streptomycin added) under standard conditions. Cell diameter was measured in a Vi-CELL Cell Viability Analyser (Beckman Coulter, High Wycombe, UK).

Western blotting. Cell and tumour lysates were analysed by western blotting, as described previously (Han et al, 2008). Cell and tumour lysate protein was transferred onto Immobilon-P membranes (Millipore; Bedford, MA, USA). Blots were incubated with caspase-3 antibody (Cell Signaling, Beverly, MA, USA), cleavedPARP (Cell Signaling), MCT-1 (Millipore), p4E-BP1 (Cell Signaling), S6 ribosomal protein (Cell Signaling), pS6 ribosomal protein (Cell Signaling) or LC3B antibody (Cell Signaling). The membranes were then incubated with anti-rabbit secondary antibody (GE Healthcare, Little Chalfont, UK). $\alpha$-Tubulin (Cell Signaling) and $\beta$-actin (Cell Signaling) were used as loading controls. Specific-binding antibody-target protein interactions were detected using enhanced chemiluminescence plus reagents (Amersham Biosciences, Chalfont St Giles, UK) and exposure to either Hyperfilm ECL (Amersham) or X-OMAT Kodak (Kodak, Rochester, NY, USA) autoradiography film.

Annexin V/PI analysis. In all, $5 \times 10^{5}$ cells were resuspended in binding buffer, incubated at $25^{\circ} \mathrm{C}$ for $5 \mathrm{~min}$ in the dark with $5 \mu \mathrm{l}$ fluorescein isothiocyanate-annexin- $\mathrm{V}$ and $5 \mu \mathrm{l}$ propidium iodide (PI) (BioVision, Mountain View, CA, USA), and analysed by fluorescence activated cell sorting (FACS, BD LSRII flow cytometer, BD Biosciences, Oxford, UK) to determine annexin-V binding and PI exclusion. The population of cells with low annexin-V/low PI staining were defined as viable cells, high annexin-V/low PI staining as early apoptotic cells and high annexin-V/high PI staining as late apoptotic or necrotic cells.

Cell-cycle analysis. A total of $2 \times 10^{6}$ cells were fixed with $70 \%$ ethanol for $30 \mathrm{~min}$ at $4{ }^{\circ} \mathrm{C}$ and incubated with $100 \mu \mathrm{g} \mathrm{ml}^{-1}$ RNAase and $40 \mu \mathrm{g} \mathrm{ml}^{-1}$ PI in phosphate-buffered saline for $30 \mathrm{~min}$ at $37^{\circ} \mathrm{C}$. DNA histograms were generated by FACS analysis.

Electron microscopy. Cells were grown in 13-mm dishes and fixed for $4 \mathrm{~h}$ in $2.5 \%$ glutaraldehyde fixative in phosphate buffer at $4{ }^{\circ} \mathrm{C}$. After fixation, cell monolayers were placed in glutaraldehyde wash solution and then postfixed in Millonigs Osmium Tetroxide fixative for 15-30 min. The cultures were dehydrated through a graded series of $10 \%$ to $100 \%$ ethanol, infiltrated and then embedded in medium TAAB Premix Resin. Ultrathin sections were collected on copper grids and stained with uranyl acetate and lead citrate. Sections were viewed using a Hitachi H7600 
transmission electron microscope (Hitachi High-Technologies Corporation, Tokyo, Japan).

ROS measurements. OxiSelect ROS assay kit (Cell Biolabs, Inc., San Diego, CA, USA) was used in this experiment according to the protocol provided by the manufacturer. ROS levels were measured in HT29 (100 mM), HCT116 WT (75 mM) and Bax-ko (75 mM) cells treated with DCA for $1 \mathrm{~h}$.

LDH enzymatic assay. Cellular LDH activities were measured using the standard spectrophotometric methods as previously described (Board et al, 1990). Cells were collected by standard trypsin treatment, lysed on ice in extraction buffer (triethanolamine/HCL $50 \mathrm{~mm}$, EDTA $1 \mathrm{~mm}, \mathrm{MgCl}_{2} 2 \mathrm{~mm}, \beta$-mercaptoethanol $26 \mathrm{~mm}$ ) and centrifuged at $16000 \mathrm{~g}$ for $10 \mathrm{~min}$ to give total protein concentrations in the supernatants of about $5 \mathrm{mg} \mathrm{ml}^{-1}$. Reactions were started by adding assay solutions (triethanolamine/HCL $60 \mathrm{~mm}$, NADH $0.17 \mathrm{~mm}$, sodium pyruvate $0.4 \mathrm{~mm}$, triton $0.05 \%$ ), and the activities of $\mathrm{LDH}$ enzymes were measured spectrophotometrically at $340 \mathrm{~nm}$, with enzymatic activities measured in nmol $\min ^{-1}$ per million cells.

$\mathrm{NAD}^{+}$and NADH measurements. Total cellular $\mathrm{NAD}^{+} / \mathrm{NADH}$ ratios were measured using an $\mathrm{NAD}^{+} / \mathrm{NADH}$ quantification kit (BioVision), according to the protocol provided by the manufacturer.

${ }^{1} \mathrm{H}$-MRS of culture medium and cell extracts. ${ }^{1} \mathrm{H}$-MRS was performed on a Bruker $500 \mathrm{MHz}$ spectrometer (Bruker Biospin, Ettlingen, Germany). ${ }^{1} \mathrm{H}-\mathrm{MRS}: 7500 \mathrm{~Hz}$ spectral width, 16384 time domain points, 128 scans, temperature $298 \mathrm{~K}$, acquisition time approximately $5 \mathrm{~min}$. The water resonance was suppressed by a gated irradiation centred on the water frequency. Spectral processing was carried out using the Bruker Topspin-3 software package (Bruker Biospin, Coventry, UK). Cells were extracted by perchloric acid or dual-phase extraction procedures as previously described (Tyagi et al, 1996; Chung et al, 2003). Water-soluble extracts were freeze-dried and reconstituted in $700 \mu$ l deuterated water $\left(\mathrm{D}_{2} \mathrm{O}\right.$, Sigma Aldrich), and the extracts $(500 \mu \mathrm{l})$ were then placed in $5 \mathrm{~mm}$ NMR tubes. In all, $50 \mu \mathrm{l}$ of $0.75 \%$ sodium 3-trimethylsilyl-2,2,3,3-tetradeuteropropionate (TSP) in $\mathrm{D}_{2} \mathrm{O}$ (Sigma Aldrich) was added to the samples for chemical shift calibration and quantification. Media from the cultured cells were also analysed by ${ }^{1} \mathrm{H}-\mathrm{MRS}$, a $500-\mu \mathrm{l}$ sample of culture media and a $50-\mu \mathrm{l}$ of $\mathrm{D}_{2} \mathrm{O}$ were placed in a NMR tube and $50 \mu \mathrm{l}$ of $0.75 \%$ TSP in $\mathrm{D}_{2} \mathrm{O}$ was added to the samples for chemical shift calibration and quantification. Spectral assignments were based on literature values (Sitter et al, 2002).

In vitro DNP ${ }^{13} \mathrm{C}$-MRS studies. $\left[1-{ }^{13} \mathrm{C}\right]$ pyruvic acid containing $15 \mathrm{~mm}$ OX63 free radical was polarised in a HyperSense DNP polariser (Oxford Instruments Molecular Biotools, Abingdon, UK) at $3.35 \mathrm{~T}$ and $1.4 \mathrm{~K}$ as described previously (Golman et al, 2006a). The polarised sample was dissolved in a neutralised phosphatebuffered solution containing $50 \mathrm{~mm}$ unlabelled lactate and $1 \mathrm{~mm}$ EDTA. In all, $100 \mu \mathrm{l}\left[1-{ }^{13} \mathrm{C}\right]$ pyruvate solution was added to a $500-\mu \mathrm{l}$ suspension of control, DCA treated or recovered cells $(\sim 80-100$ million cells) in a 5-mm NMR tube with or without DCA added to the suspension medium, resulting in a final concentration of $8 \mathrm{~mm}$ polarised pyruvate and $8 \mathrm{~mm}$ unlabelled lactate, after which serial ${ }^{13} \mathrm{C}-\mathrm{MRS}$ spectra were acquired using a $500 \mathrm{MHz}$ spectrometer (Bruker Biospin, Ettlingen, Germany) at $125 \mathrm{MHz}$ in a multinuclear (BBO) probe every $2 \mathrm{~s}$ with a $10^{\circ}$ angle radio-frequency pulse.

Kinetic analysis of in vitro hyperpolarised data. Serial spectra were phase and baseline corrected and integrated using the XWinNMR software (Bruker Biospin, Coventry, UK). The integrated peak areas from the pyruvate/lactate experiments were plotted as a function of time, and apparent reaction rates were obtained by least-squares fitting of the data to the modified Bloch equations using a two-site exchange model as previously described (Hill et al, 2013a,b). All apparent rate constants for the forward reaction of conversion of pyruvate-to-lactate $\left(k_{\mathrm{PL}}\right)$ are presented as a mean concentration per second normalised to the number of cells.

In vivo HT29 xenograft model. HT29 carcinoma cells $\left(5 \times 10^{6}\right)$ were injected and propagated subcutaneously in the flank of $\mathrm{NCr}$ female nude mice. Tumour volume was calculated by measuring the length, width and depth using calipers and the formula $L \times$ $W \times D \times(\pi / 6)$. Once an appropriate tumour volume $\left(\sim 300 \mathrm{~mm}^{3}\right)$ was established, mice were randomly divided into two groups; one group was treated with $200 \mathrm{mg} \mathrm{kg}^{-1}$ DCA p.o. once daily for 4 days $(n=7)$ and another group with vehicle (saline) alone $(n=6)$. Tumour volumes were measured daily to assess the anti-tumour effect of DCA on HT29 xenografts. Tumours were then harvested $4 \mathrm{~h}$ after the last dose for western blotting analysis. A separate cohort of mice (three vehicle- and three DCA-treated for 3 days) was used for the in vivo DNP ${ }^{13} \mathrm{C}$-MRS study. All procedures performed on mice were approved by the Institute of Cancer Research Ethical Review Committee and with the authority of Personal and Project Licences issued by the UK Home Office under the Animals (Scientific Procedures) Act 1986 and in accordance with the United Kingdom National Cancer Research Institute guidelines for the welfare of animals in cancer research (Workman et al, 2010).

In vivo DNP ${ }^{13} \mathrm{C}-\mathrm{MRS}$ study. In vivo MRS was performed on a Philips 3T Achieva clinical scanner (Philips Healthcare, Guildford, UK). Mice bearing HT29 xenografts (volume of 250-300 $\mathrm{mm}^{3}$ ) were positioned with their tumour within a $2-\mathrm{cm}$ diameter ${ }^{13} \mathrm{C}$ transmit/receive surface coil at the isocentre of the scanner. ${ }^{1} \mathrm{H}-\mathrm{MR}$ imaging was performed using a human endorectal coil placed adjacent to the mouse. ${ }^{1} \mathrm{H}$ shimming was carried out using an iterative VOI protocol on an axial slice encompassing the whole tumour (voxel size $10 \times 10 \times 10 \mathrm{~mm}^{3}$ ). ${ }^{1} \mathrm{H}-\mathrm{MR}$ imaging was used to plan the ${ }^{13} \mathrm{C}$ slice selective spectroscopy geometry and obtain reference images to calculate the tumour volume that was included within the ${ }^{13} \mathrm{C}-\mathrm{MR}$ spectroscopy slice (measured using the volume rendering tool in OsiriX (Pixmeo Sarl, Bernex, Switzerland)). The hyperpolarised $\left[1-{ }^{13} \mathrm{C}\right]$ pyruvic acid was dissolved in $4 \mathrm{ml}$ Trizma buffer containing $80 \mathrm{~mm}$ sodium hydroxide, $1 \mathrm{~mm}$ EDTA and $50 \mathrm{~mm}$ sodium chloride, resulting in a $80-\mathrm{mm}$ $\left[1-{ }^{13} \mathrm{C}\right]$ pyruvate solution. An aliquot of this solution was tested for $\mathrm{pH}(\mathrm{pH} 7)$ and temperature $\left(37^{\circ} \mathrm{C}\right)$ before injection. Following the quality control check, $175 \mu$ l hyperpolarised $\left[1-{ }^{13} \mathrm{C}\right]$ pyruvate was administered in situ via a lateral tail vein over approximately $5 \mathrm{~s}$. A series of $128{ }^{13} \mathrm{C}$-MR spectra were recorded at $32 \mathrm{MHz}$ every $3 \mathrm{~s}$ using a $20^{\circ}$ slice selective pulse-and-acquire sequence $(10 \mathrm{~mm}$ slice thickness, 1 transient, 2048 time domain points, $8 \mathrm{kHz}$ spectral width). In vivo $\mathrm{DNP}{ }^{13} \mathrm{C}$-MRS measurement of tumours was performed on day 0 (before treatment), and mice were then treated on days 1 and 2 with $200 \mathrm{mg} \mathrm{kg}^{-1}$ DCA or saline p.o. and a final dose was given $1 \mathrm{~h}$ before the posttreatment measurement (Day 3).

Postprocessing of in vivo ${ }^{13} \mathrm{C}$-MRS spectra. Spectra were zero filled to 4096 points and line broadened by $30 \mathrm{~Hz}$. Metabolite peaks were quantified using the Amares fitting tool in jMRUI (http://sermn02.uab.es). Previous knowledge was used to initialise the time-domain fitting using the Amares software (http:// sermn02.uab.es). Soft-constraint values were supplied for the frequency range, linewidth and peak amplitudes, and the phase of all of the peaks was fixed. Peak areas were exported from jMRUI as text files, and kinetic modelling was performed using Matlab (Mathworks, UK) by fitting to the time series of peak areas. These time series were modelled according to the modified Bloch equations and fitted using maximum likelihood estimation. 
A raised cosine input function was used to model the pyruvate bolus. Data were fitted with a three-site (signals from pyruvate, lactate and alanine were fitted), two-way kinetic model (Hill et al, 2013b). Rates were normalised to the tumour volume included within the spectroscopy acquisition slice.

The kinetic model included alanine as it is measurable in the spectra and pyruvate can be converted to alanine and vice versa. If alanine is not included in the kinetic model, it may bias the apparent forward and backward pyruvate and lactate exchange rates. The alanine data are not presented here, because the conversion of pyruvate to alanine is not of direct relevance in this study.

Statistical analysis. Data are presented as the mean \pm s.e.m. For comparison of metabolic exchange rate constants, metabolite concentrations and ratios, the Student's $t$-test was used with a $P$-value of $\leqslant 0.05$ considered to be statistically significant. All statistical tests were two-tailed.

\section{RESULTS}

TRAIL induces apoptosis in HCT116 WT but not in HCT116 Bax-ko cells confirming the failure of HCT116 Bax-ko to undergo apoptosis. Apoptosis was induced in HCT16 WT cells after $24 \mathrm{~h}$ of TRAIL treatment, as confirmed by markedly increased cleaved-PARP (Figure 1A). Negligible cleaved PARP was apparent in the HCT116 Bax-ko cells after TRAIL treatment, indicating that no apoptosis had occurred (Figure 1A).

DCA causes cell cycle arrest and reduction in cell number when compared with controls. Representative flow cytometry analysis histograms showing cell cycle distribution of vehicle- (saline) and DCA-treated HCT116 WT cells are illustrated in Figure 1B. Cell cycle analysis by flow cytometry demonstrated that DCA caused a G2 arrest in HCT116 WT and HCT116 Bax-ko cells. G1 arrest was observed in HT29 and PC3 cells (Figure 1C). No significant change in cell size was observed in the treatment groups when compared with controls. A significant reduction in adherent cell number was found in all the treatment groups (Figure 1D). Following $48 \mathrm{~h}$ of recovery from DCA treatment, the cell number significantly increased in HCT116 Bax-ko cells and returned toward control levels in HCT116 WT cells when compared with control cells after $24 \mathrm{~h}$ of vehicle treatment (Figure 1D).

DCA induces autophagy in cancer cells. Treatment of HT29, PC3, HCT116 WT and HCT116 Bax-ko cells with DCA for $24 \mathrm{~h}$ caused low levels of necrosis and apoptosis in all the treatment groups when compared with controls as shown by Annexin $\mathrm{V}$ and PI staining (Figure 2A) and by western blottings (Figure 2B). Twenty-four hours of DCA treatment was found to induce autophagy in all cell lines studied, as confirmed by the overexpression of LC3B II in western blottings (Figure 2B). Electron microscopy revealed the presence of double-membrane autophagosomes in all the treated groups, indicating the occurrence of autophagy (Figure 3). Cell recovery from DCA-induced autophagy was found to be time dependent, as shown by the LC3B II band in the western blots of HCT116 Bax-ko and WT cells (Figure 4A and B), and consistent with the reversible nature of this process. A recovery time of $48 \mathrm{~h}$ after the cessation of DCA treatment was used for further MRS studies, as the levels of LC3B II expression were similar to controls at this time point.

DCA treatment leads to increased levels of ROS. In order to determine whether increased ROS production is an early event that could trigger autophagy, ROS levels were measured in all DCAtreated colorectal cancer cells after $1 \mathrm{~h}$ of treatment. Increased ROS production was found in HT29 (212 $\pm 4 \%$ of control; $P<0.0001)$,
A

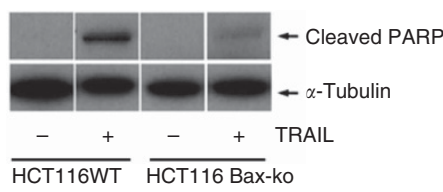

B

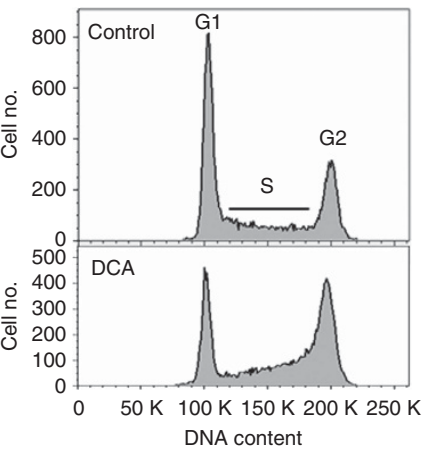

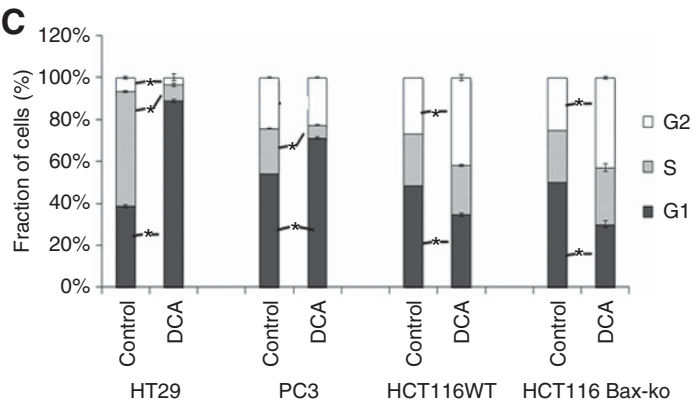

D

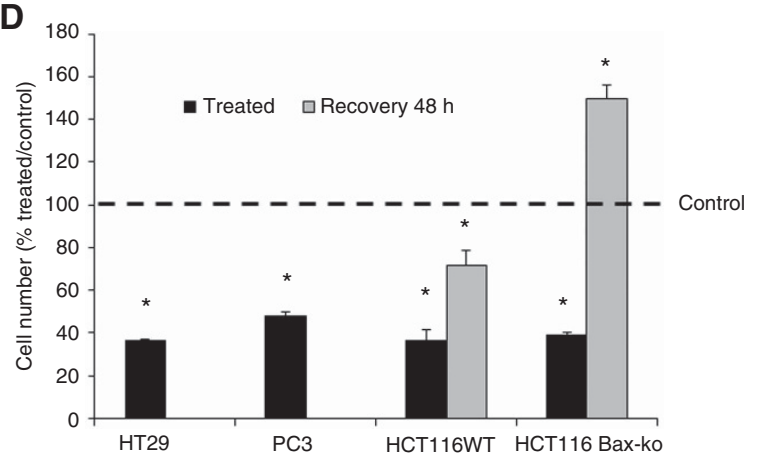

Figure 1. Cellular response to TRAIL and DCA treatment in cancer cells. (A) Western blots of c-PARP and $\alpha$-tubulin in HCT116 WT and HCT116 Bax-ko cells following $24 \mathrm{~h}$ of $30 \mathrm{ng} \mathrm{ml}^{-1}$ TRAIL treatment. (B) Representative flow cytometry histograms showing cell cycle distribution in vehicle-treated (saline), top, and $24 \mathrm{~h}$ DCA-treated, bottom, HCT116 WT cells. (C) Cell cycle analysis showing the percentage of cells in G1, S and G2 phase in vehicle- and DCA-treated HT29, PC3, HCT116 WT and HCT116 Bax-ko cells (mean \pm s.e.m. minimum $n=3$ in each group, ${ }^{*}<0.01$ ). (D) Cell number (\% treated/control) for 24-h DCA-treated HT29, PC3, HCT116 WT and HCT116 Bax-ko cells and 48-h recovered HCT116 WT and HCT116 Bax-ko cells (mean \pm s.e.m. minimum $n=3$ in each group, ${ }^{\star} P<0.01$ ). 


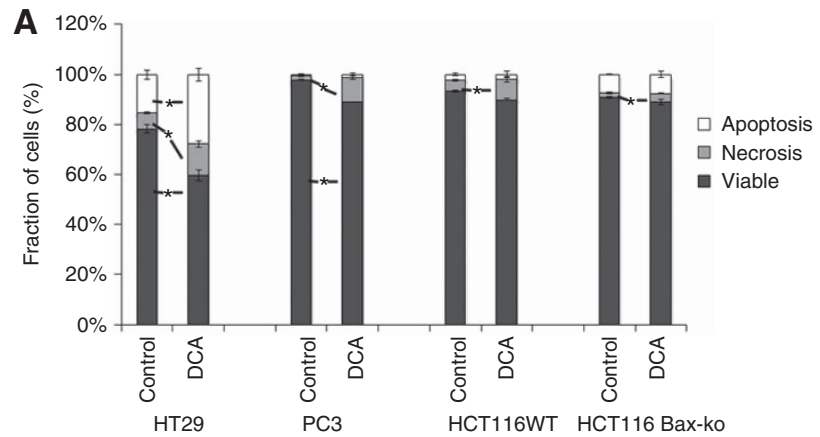

B

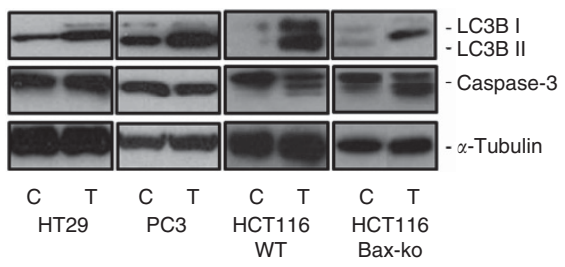

Figure 2. Autophagy is induced in DCA-treated cancer cells with minimal apoptosis and necrosis. (A) Annexin $V$ and propidium iodide staining $(\mathrm{PI})$ to measure the proportion of cells undergoing apoptosis and necrosis in HT29, PC3, HCT116 WT and HCT116 Bax-ko cells following $24 \mathrm{~h}$ of DCA treatment. Data are expressed as mean percentage \pm s.e.m. (minimum $n=3$ in each group). Statistically significant changes are indicated $\left({ }^{\star} P<0.05\right)$. (B) Western blots of LC3B, caspase- 3 and $\alpha$-tubulin in HT29, PC3, HCT116 WT and HCT116 Bax-ko cells following $24 \mathrm{~h}$ of DCA treatment.

HCT116 Bax-ko (131 $\pm 2 \%$ of control; $P<0.004)$ and HCT116 WT (147 $\pm 10 \%$ of control; $P<0.0001$ ) cells (Figure $4 \mathrm{C}$ ).

DCA treatment causes mTOR inhibition. In order to investigate the molecular effects and the possible drivers that induced autophagy following DCA treatment, the mTOR pathway was examined in DCA-treated colorectal cancer cells. Western blotting analysis for total S6 ribosomal protein, pS6 ribosomal protein and p4E-BP1 (molecular biomarkers for mTOR inhibition) was performed on control and DCA-treated HT29, HCT116 Bax-ko and HCT116 WT cells. Decreased expression levels of pS6 ribosomal protein and $\mathrm{p} 4 \mathrm{E}-\mathrm{BP} 1$ and no change in total S6 ribosomal protein were found in all DCA-treated cells when compared with controls (Figure 4D), confirming that mTOR inhibition occurred following DCA treatment.

DCA treatment reduces lactate excretion with no change in glucose uptake. In order to examine the Warburg effect in DCAtreated cancer cells, culture media from HT29, PC3, HCT116 WT and HCT116 Bax-ko cells following $24 \mathrm{~h}$ of DCA treatment and from control cell cultures were analysed by ${ }^{1} \mathrm{H}$-MRS. Significant reductions in lactate excretion $(P<0.0001)$ were observed in all the DCA treatment groups when compared with controls (Figure 5). Lactate excretion in HCT116 Bax-ko and HCT116 WT cells returned to and above the 24-h saline-treated control values, respectively (Figure 5), when the cells had recovered for $48 \mathrm{~h}$ from DCA-induced autophagy. Glucose uptake remained unchanged in all DCA-treated cells and in recovered HCT116 Bax-ko cells and was higher than controls in recovered HCT116 WT cells (Figure 5). Our data showed that both apoptosis proficient and defective cell lines are able to recover from DCA-induced autophagy and that this process is reversible.

DCA causes reduction in apparent $k_{\mathrm{PL}}$ in cancer cells. In order to assess pyruvate kinetics in DCA-treated cells, hyperpolarised $\left[1-{ }^{13} \mathrm{C}\right]$ pyruvate to lactate exchange was monitored by ${ }^{13} \mathrm{C}-\mathrm{MRS}$ in
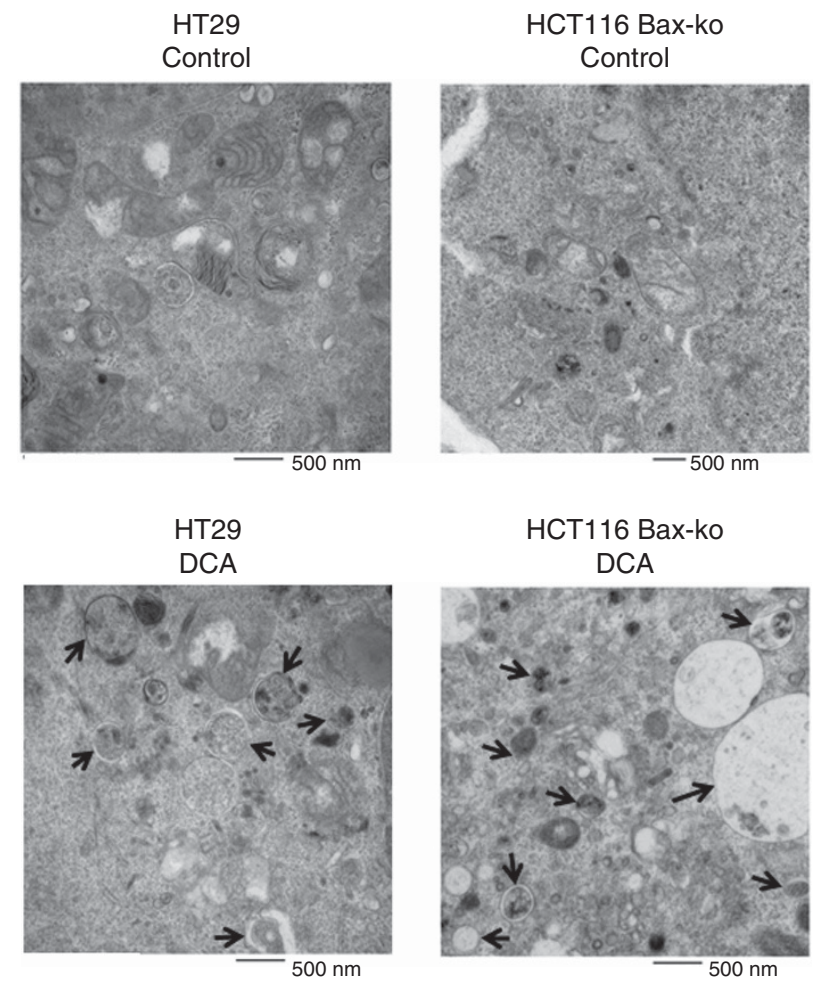

Figure 3. Electron microscopy images of autophagic vacuoles in control and DCA-treated HT29 and HCT116 Bax-ko cells. Black arrows illustrate some of the autophagic vacuoles at different stages of the autophagy process.

real-time. HCT116 Bax-ko, HT29 and PC3 cells were treated with DCA for $24 \mathrm{~h} .{ }^{13} \mathrm{C}$-MR spectra and the kinetics of $k_{\mathrm{PL}}$ from control, DCA-treated and recovered HCT116 Bax-ko cell suspensions after the addition of hyperpolarised $\left[1-{ }^{13} \mathrm{C}\right]$ pyruvate are illustrated in Figure 6A-C. Significant reductions in $k_{\mathrm{PL}}$ were found in all the treatment groups $(P<0.005$; Figure 6D). No pyruvate conversion to bicarbonate was observed in any of the experiments. A significant increase in $k_{\mathrm{PL}}$ to greater than control rates was observed in HCT116 Bax-ko cells after recovery from DCAinduced autophagy $(P<0.001$; Figure 6A-D).

Increased $\mathrm{LDH}$ activity, $\mathrm{NAD}^{+} / \mathrm{NADH}$ ratio, $\mathrm{NAD}^{+}$level and MCT-1 expression in DCA-treated cells. Significant increases in $\mathrm{LDH}$ activity were found in all of the three cell lines after DCA treatment (Figure 7A). Total intracellular $\mathrm{NAD}(\mathrm{H})$ pool levels (measured by ${ }^{1} \mathrm{H}-\mathrm{MRS}$ ) were unchanged in DCA-treated cells except for the DCA-treated HT29 cells and recovered HCT116 Bax-ko cells where increases in intracellular $\mathrm{NAD}(\mathrm{H})$ were observed (Figure 7B). Levels of $\mathrm{NAD}^{+}$and $\mathrm{NADH}$ and $\mathrm{NAD}^{+} /$ NADH ratios were further examined in DCA-treated HT29 and HCT116 Bax-ko cells using a $\mathrm{NAD}^{+} / \mathrm{NADH}$ kit. Increased $\mathrm{NAD}^{+} / \mathrm{NADH}$ ratios were found in HT29 (166 $\pm 21 \%$ of control; $P=0.006)$ and HCT116 Bax-ko cells $(170 \pm 19 \%$ of control; $P=0.03$ ) following $24 \mathrm{~h}$ of DCA treatment, and this ratio returned to control levels by $48 \mathrm{~h}$ of recovery (Figure $7 \mathrm{C}$ ). The observed increased $\mathrm{NAD}^{+} / \mathrm{NADH}$ ratio during DCA treatment is due to a rise in $\mathrm{NAD}^{+}$level in HT29 $(180 \pm 22 \%$ of control; $P=0.01)$ and HCT116 Bax-ko cells $(179 \pm 19 \%$ of control; $P=0.03)$ coupled with no change in NADH level (Figure 7D). In HCT116 Bax-ko cells recovered from DCA treatment, the $\mathrm{NAD}^{+}$level was further elevated ( $332 \pm 62 \%$ of control; $P=0.007)$ with increased $\mathrm{NADH}$ (336 $\pm 92 \%$ of control; $P=0.007$ ) (Figure $7 \mathrm{D}$ ) and therefore no significant change in $\mathrm{NAD}^{+} / \mathrm{NADH}$ ratio (Figure $7 \mathrm{C}$ ). 
A

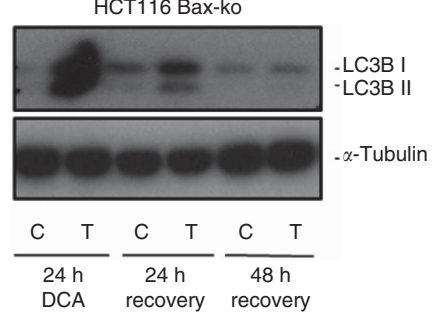

C

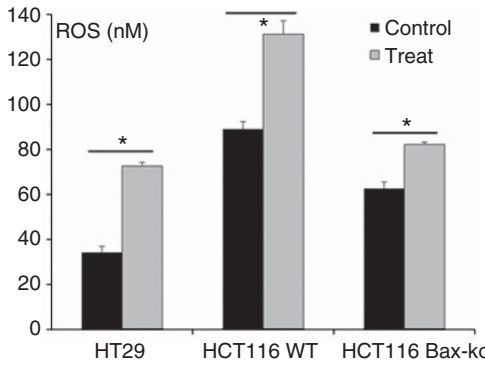

B

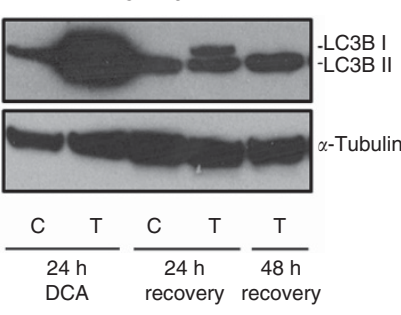

D

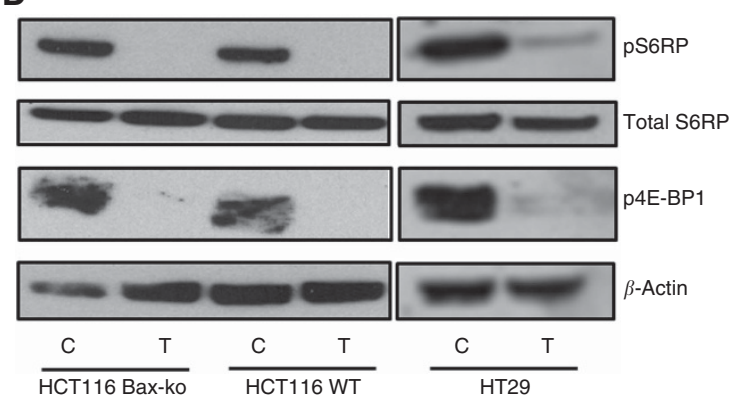

Figure 4. DCA treatment induced ROS production and mTOR inhibition in cancer cells and DCA-induced autophagy is reversed by 48-h after cessation of treatment. Western blots of LC3B and $\alpha$-tubulin in 24-h vehicle-treated, 24-h DCA-treated and 48-h DCA-recovered (A) HCT116 Bax-ko and (B) HCT116 WT cells. (C) Increase in reactive oxygen species (ROS) production following 1-h DCA treatment in HT29, HCT116 WT and HCT116 Bax-ko cells (mean \pm s.e.m. $n=4$ per group, ${ }^{\star} P<0.005$ ). (D) Western blots of pS6 ribosomal protein, total $S 6$ ribsomal protein, p4E-BP1 and $\beta$-actin (loading control) in DCA-treated HCT116 Bax-ko, HCT116 WT and HT29 cells, indicating that mTOR is downregulated.

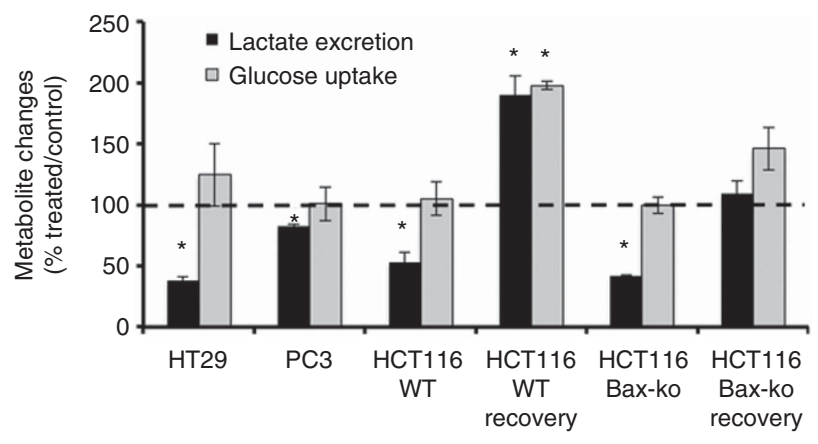

Figure 5. Excreted lactate levels and glucose uptake measured by ${ }^{1} \mathrm{H}-\mathrm{MRS}$ in 24-h DCA-treated HT29, PC3, HCT116 WT and HCT116 Bax-ko cells and at $48 \mathrm{~h}$ recovery following $24 \mathrm{~h}$ of DCA treatment in HCT116 WT and HCT116 Bax-ko cells as compared with respective 24-h vehicle-treated control. Data are expressed as mean percentage ratio \pm s.e.m. (minimum $n=3$ in each group). Statistically significant changes are indicated $\left({ }^{\star} P<0.0001\right)$.

We then examined the MCT-1 expression level in HCT116 Baxko cell, and an increase in MCT-1 expression was found in those cells following $24 \mathrm{~h}$ of DCA treatment, and it remained above control level after $48 \mathrm{~h}$ of recovery (Figure 7E).

DCA is a possible competitive MCT-1 inhibitor. The dramatic drop in the apparent rate constant $k_{\mathrm{PL}}$ following DCA treatment could be in part due to competitive inhibition of MCT-1 by the high concentrations of DCA in the medium, as DCA is a monocarboxylate anion and a structural analogue of pyruvate. We measured $k_{\mathrm{PL}}$ in HCT116 Bax-ko cells following $24 \mathrm{~h}$ DCA treatment for cells resuspended in culture medium, either with or without DCA added. A significant reduction in the $k_{\mathrm{PL}}$ was found in DCA-treated HCT116 Bax-ko cells without DCA added to the medium $\left(0.32 \pm 0.02 \mathrm{nmol} \mathrm{s}^{-1}\right.$ million cells $\left.{ }^{-1}\right)$, when compared with control rates $\left(0.57 \pm 0.03 \mathrm{nmol} \mathrm{s}^{-1}\right.$ million cells ${ }^{-1}$;
$P<0.001$; Figure $6 \mathrm{~A}$ and $\mathrm{D})$. The $k_{\mathrm{PL}}$ of DCA-treated HCT116 Bax-ko cells without DCA added to the medium was significantly higher than that with DCA present in the medium $\left(0.18 \pm 0.02 \mathrm{nmol} \mathrm{s}^{-1}\right.$ million cells ${ }^{-1} ; P<0.01$; Figure $6 \mathrm{~A}$ and $\left.\mathrm{D}\right)$.

DCA treatment induces autophagy and reduces $k_{\mathrm{PL}}$ in HT29 xenografts. We examined the cellular and metabolic effects and efficacy of DCA treatment in HT29 tumours in vivo. Significant differences in tumour volumes were found after 3 days of treatment between the vehicle- and DCA-treated groups, indicating that DCA treatment causes a significant growth delay in HT29 xenografts. Following 3 days of treatment, tumour volumes increased by $17 \% \pm 3 \%$ in the vehicle group and by $2 \% \pm 3 \%$ in the DCA-treated group $(P=0.005 ;$ Figure $8 \mathrm{~A})$. DCA-treated tumour volume remained static $(0.4 \% \pm 3 \%)$, whereas vehicle-treated tumour volume increased to $28 \% \pm 4 \%$ by 4 days of DCA treatment $(P=0.0004$; Figure $8 \mathrm{~A})$. Induction of autophagy (as shown by the increased expression of LC3B) was found in DCA-treated HT29 tumours when compared with vehicle controls, with minimal apoptosis as observed by the absence of cleaved PARP (Figure 8B).

A transverse image of a mouse with a subcutaneous HT29 xenograft (tumour outlined) is shown in Figure 8C, with the acquisition slice for ${ }^{13} \mathrm{C}$-MRS indicated (grey lines). Representative in vivo ${ }^{13} \mathrm{C}-\mathrm{MR}$ spectra acquired from the same HT29 tumour xenograft pre- and post-DCA treatment are shown in Figure 8D. The full width at half maximum of the $\left[1-{ }^{13} \mathrm{C}\right]$ pyruvate peak was $31 \mathrm{~Hz}$. Resonances from $\left[1-{ }^{13} \mathrm{C}\right]$ lactate, $\left[1-{ }^{13} \mathrm{C}\right]$ pyruvate hydrate, $\left[1-{ }^{13} \mathrm{C}\right]$ alanine and $\left[1-{ }^{13} \mathrm{C}\right]$ pyruvate are seen. There is also a small resonance at 161 p.p.m. that is attributed to ${ }^{13} \mathrm{C}$ bicarbonate but was too small to reliably quantify using the Amares fitting protocol. There is a linear phase shift in the spectrum as a result of chemical shift evolution during the time delay between excitation and acquisition that is required for the application of slice selective gradients.

Figure $8 \mathrm{E}$ shows a representative example of the peak areas from a dynamic time series of spectra. The solid lines show the fits from a two-way, three-site exchange model based on the modified Bloch equations (Hill et al, 2013b). Residuals show that the kinetic model 
A

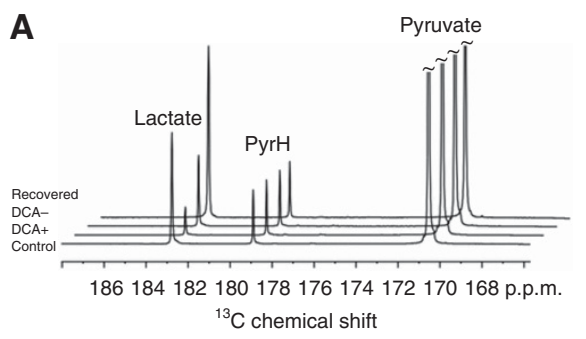

C

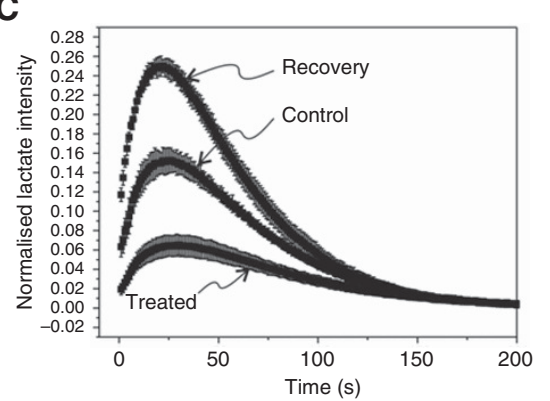

B

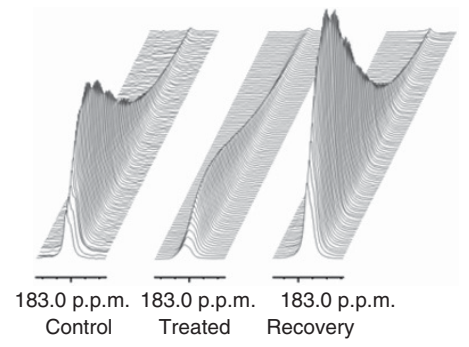

$\mathbf{D}_{1}$

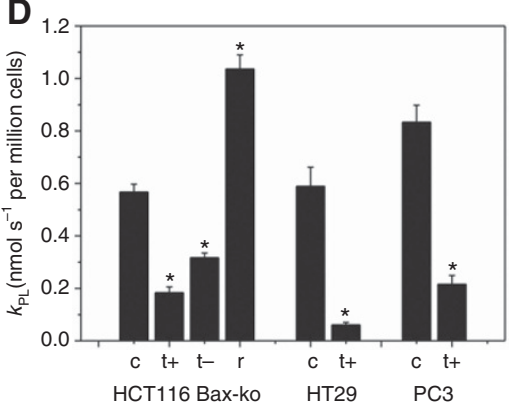

Figure 6. In vitro hyperpolarised ${ }^{13} \mathrm{C}$-MRS assay of DCA-treated and recovered cancer cells. (A) Hyperpolarised ${ }^{13} \mathrm{C}-\mathrm{MR}$ spectra from an $\mathrm{HCT} 116$ Bax-ko cell assay showing the sum over the entire dynamic time series from a control cell experiment and following 24-h DCA treatment with ( + ) and without (-) DCA added to the final cell suspension medium and after 24-h DCA treatment followed by 48-h cell recovery. The spectrum displays peaks from pyruvate, lactate and pyruvate hydrate (PyrH). (B) Representative time courses of the lactate peak in vehicle-treated,

DCA-treated and recovered cells. (C) Plot of the lactate peak integral as a function of time normalised to the pyruvate peak integral at time $t=0 \mathrm{~s}$ and normalised per million cells acquired for HCT116 Bax-ko control cells, 24-h DCA treatment and 24-h DCA treatment followed by 48-h recovery. (D) Kinetics of the apparent forward reaction rate constant $k_{\mathrm{PL}}$ of pyruvate-to-lactate exchange derived from fitting of the experimental data and normalised to cell number ( \pm s.e.m.) for vehicle-control and 24-h DCA-treated HT29, PC3 and HCT116 Bax-ko cells and its 48-h recovery (minimum $n=3$ in each group). Statistically significant changes are indicated ( $\left.{ }^{*} P<0.01\right)$. Keys c: vehicle (saline)-treated; $t+: 24-h$ DCA-treated cells with DCA added in the medium of the cell suspension for the DNP measurements; $t-:$ 24-h DCA-treated cells without DCA added in the medium of the cell suspension for the DNP measurements.

A

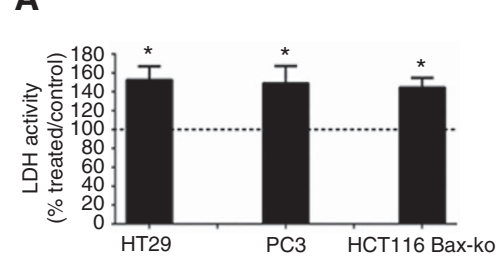

D

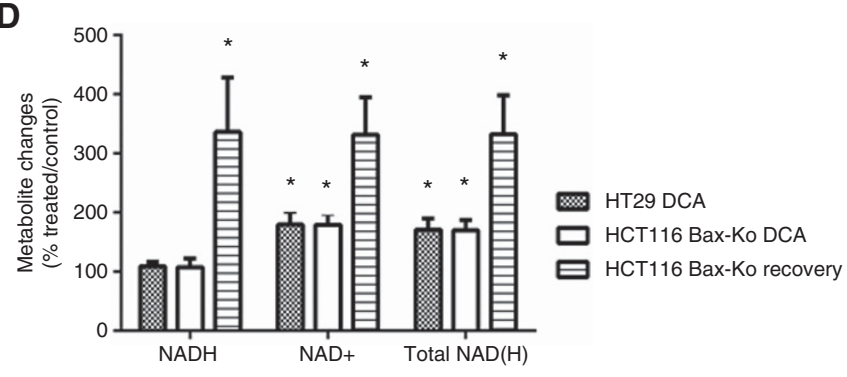

B

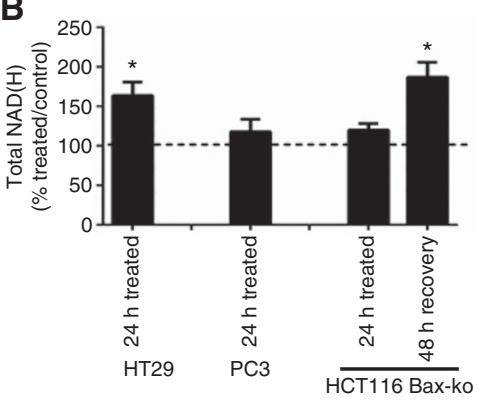

E
C
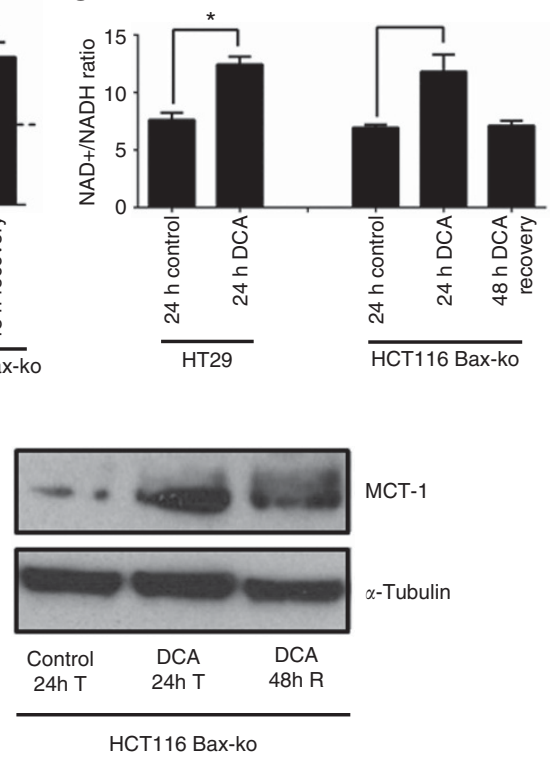

Figure 7. LDH activity, total NAD(H) pool, NAD + /NADH ratio and MCT-1 expression in DCA-treated and recovered cancer cells. (A) LDH activity (\% treated/control) in DCA-treated HT29, PC3 and HCT116 Bax-ko cells (minimum $n=5$ in each group). (B) Total NAD(H) levels (\% treated/ control) measured in cell extracts from DCA-treated HT29, PC3 cells and DCA treated and recovered HCT116 Bax-ko by ${ }^{1} \mathrm{H}-\mathrm{MRS}$ ( $n=5$ in each group). (C) NAD ${ }^{+} / \mathrm{NADH}$ ratios in DCA-treated HT29 and DCA-treated and 48-h recovered HCT116 Bax-ko cells ( $n=3$ in each group). (D) NADH, $\mathrm{NAD}^{+}$and Total NAD(H) pool (\% treated/control) in DCA-treated HT29 and DCA-treated and 48-h recovered HCT116 Bax-ko cells ( $n=3$ in each group). (E) MCT-1 expression in 24-h vehicle-treated, 24-h DCA-treated and 48-h recovered HCT116 Bax-ko cells. All data are expressed as mean \pm s.e.m. $\left({ }^{\star} P<0.05\right)$. 
A

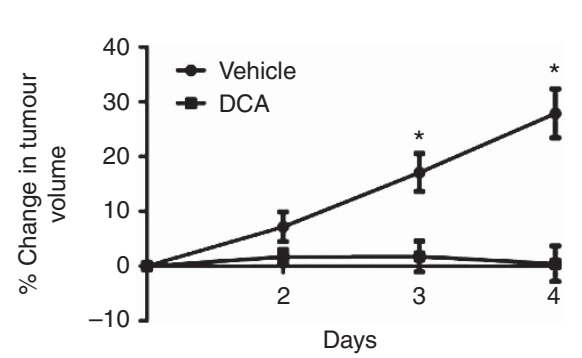

B

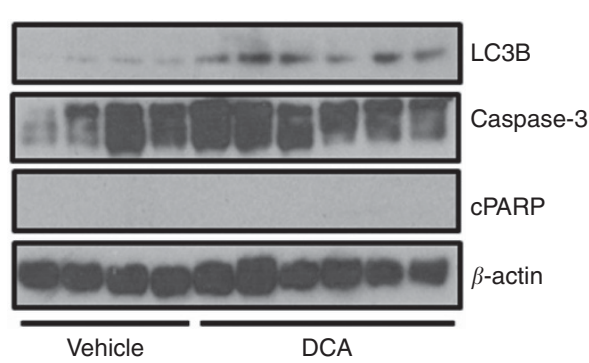

C

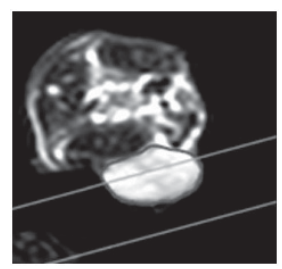

E
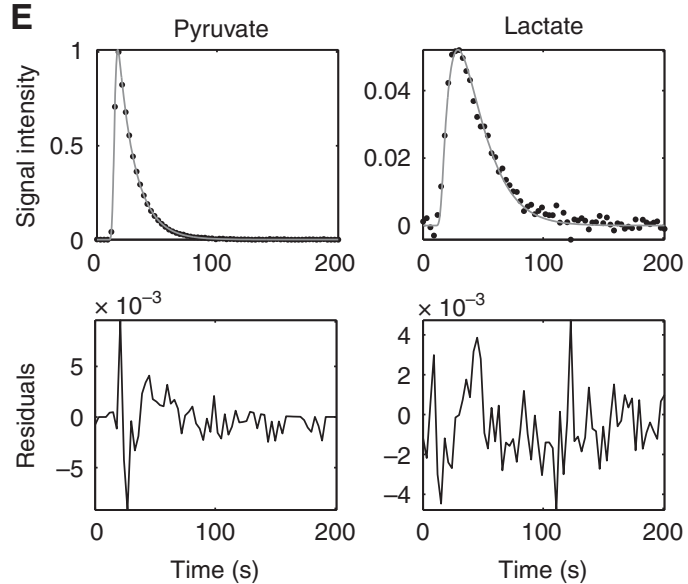

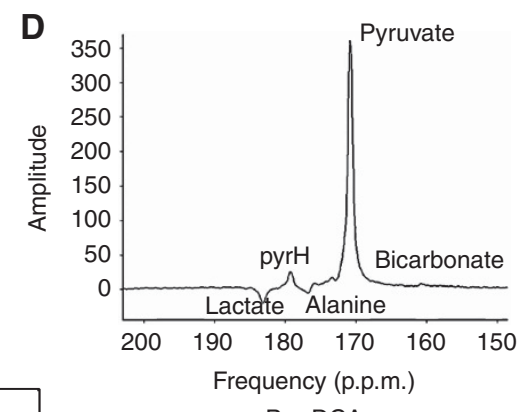

Pre-DCA

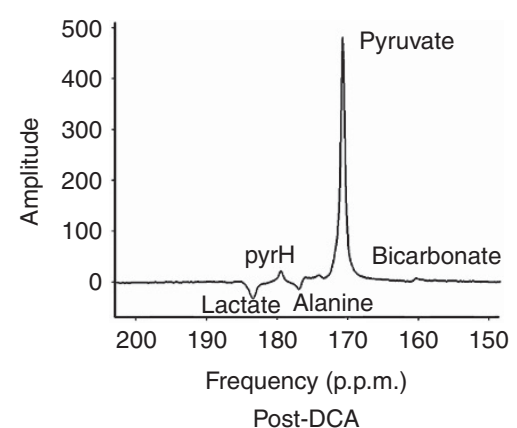

Post-DCA

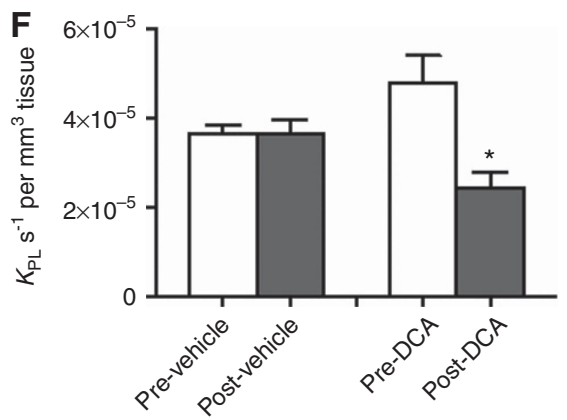

Figure 8. In vivo response to DCA treatment in HT29 xenografts. (A) Changes in HT29 tumour volumes (relative to day 1) following 4 days of treatment with vehicle $(n=6)$ or $200 \mathrm{mg} \mathrm{kg}^{-1}$ DCA via p.o. $(n=7)$. Data are expressed as mean \pm s.e.m. ${ }^{*} P \leqslant 0.005$. (B) Western blots of LC3B, caspase-3, cleaved PARP and $\beta$-actin in HT29 xenografts following 4 days of vehicle (saline, $n=4$ ) or $200 \mathrm{mg} \mathrm{kg}^{-1}$ DCA treatment $(n=6)$ via p.o. (C) Transverse image of a mouse with a subcutaneous $\mathrm{HT} 29$ xenograft (tumour outlined). The grey lines indicate the acquisition slice for ${ }^{13} \mathrm{C}-\mathrm{MRS}$. (D) Slice selective in vivo hyperpolarised ${ }^{13} \mathrm{C}-\mathrm{MR}$ spectra acquired using a surface coil on a $3 \mathrm{~T}$ clinical scanner from a HT29 xenograft pre- and post-DCA treatment. Displayed spectra are the sum of the first 24 spectra from a dynamic series acquired using a $20^{\circ}$ flip angle. There is evidence of a small bicarbonate peak at 161 p.p.m., both pretreatment and posttreatment, but it was not large enough to be included in the kinetic modelling. (E) Representative in vivo pyruvate and lactate signal areas acquired from Amares fitting in jMRUI, and three-site Matlab kinetic model fitting (solid lines) were used to obtain the apparent rate constants of pyruvate-to-lactate exchange. (F) Apparent forward rate constant of pyruvate-to-lactate exchange $k_{P L}$ for saline- (mean \pm s.e.m., $n=3$ ) and DCA-treated (mean \pm s.e.m., $n=3$ ) mice bearing subcutaneous HT29 xenografts. DCA treatment induced a significant $49 \%$ reduction in $k_{P L}\left({ }^{\star} P=0.01\right.$, paired, two-tailed Student's $t$-test). There was no significant change in $k_{P L}$ between prescans and postscans in the vehicle group.

provided a good fit to the data. In order to compare data from different tumours, the apparent rate constants obtained from kinetic modelling were normalised to the tumour volume included in the acquisition slice. Treatment with DCA induced a significant $49 \%$ reduction in $k_{\mathrm{PL}}$ when compared with the pretreatment value $(P=0.01$; Figure $8 \mathrm{~F})$. Mean $k_{\mathrm{PL}}$ pre- and post-DCA treatment were $4.80 \pm 0.61 \times 10^{-5}$ and $2.46 \pm 0.33 \times 10^{-5} \mathrm{~s}^{-1}$ per $\mathrm{mm}^{3}$ tissue volume, respectively. No significant change in $k_{\mathrm{PL}}$ was seen in the vehicle group.

\section{DISCUSSION}

To our knowledge, this is the first report showing induction of autophagy by DCA in cancer cell lines and tumour xenografts. Our study showed that DCA induces autophagy in human colorectal and prostate cancer cells with minimal apoptosis and necrosis and that these cells can subsequently recover from DCA-induced autophagy. Induction of autophagy was observed both in cell lines that have active apoptosis pathways (HCT116 WT, HT29 and PC3) as well as in a cell line where apoptosis pathways are impaired (HCT116 Bax-ko), suggesting that DCA-induced autophagy occurs independently of the cells' ability to undergo apoptosis.

We observed decreases in expression of pS6 ribosomal protein and $\mathrm{p} 4 \mathrm{E}-\mathrm{BP} 1$ protein in DCA-treated cells, indicating that $\mathrm{mTOR}$ was inhibited. mTOR inhibition is an important trigger of autophagy during stress (Jung et al, 2010), and this could be a potential mechanism of autophagy induction in DCA-treated cancer cells. We also found that DCA treatment leads to increased levels of ROS, a potential mechanism for autophagy induction in DCA-treated cancer cells. Our data are consistent with recent 
reports of mitochondrially generated ROS-activating autophagy (Chen and Gibson, 2008; Chen et al, 2009), suggesting that a modest increase in ROS production could induce autophagy. Autophagy has been reported to be induced by oxidative stress (Kroemer et al, 2010) via mechanisms including activation of PERK (Liu et al, 2008; Rzymski et al, 2009); direct oxidation and activation of Atg4 proteases (Scherz-Shouval et al, 2007); direct or indirect inhibition of mTOR (Liu et al, 2008; Alexander et al, 2010); and activation of JNK1 (Wong et al, 2010). Autophagy prevents a build-up of ROS by removal of damaged mitochondria, facilitated by accumulation of the mitochondrial kinase, PINK1, on the surface of damaged mitochondria to recruit the E3 ubiquitin ligase Parkin and the autophagy adaptor protein, p62/SQSTM1 SQSTM1 (Geisler et al, 2010; Kroemer et al, 2010; Narendra et al, 2010).

Madhock et al (2010) showed a G2 arrest in DCA-treated HT29 cells, but we observed a G1 arrest in HT29 and PC3 cells and G2 arrest in HCT116 WT and Bax-ko cells in our study. It is unclear why this is the case, and future studies are required to investigate this further. Nevertheless, the molecular and metabolic changes following DCA treatment are very similar in all of the cell lines that we have used in the present study, indicating that the changes that we observed are unlikely to be due to changes in the cell cycle.

Significantly decreased lactate excretion was observed in all DCA-treated cells with no change in glucose uptake, suggesting a reduction in Warburg effect. This reduction in the Warburg effect is due to changes in glucose utilisation rather than glucose uptake. Consistent with this finding, DNP measurements showed significant reductions in $k_{\mathrm{PL}}$ in DCA-treated cells and in vivo in DCAtreated tumours. PDK inhibition results in PDH activation and is expected to cause decreased lactate production, diverting more pyruvate into the TCA cycle. Previous publications have shown that $k_{\mathrm{PL}}$ is sensitive to a number of factors, including changes in LDH activities (Day et al, 2007; Ward et al, 2010), the availability of the enzyme co-factor $\mathrm{NAD}(\mathrm{H}), \mathrm{NAD}^{+} / \mathrm{NADH}$ ratios (Witney et al, 2011; Christensen et al, 2014) and changes in substrate concentration, for example, the endogenous concentration of lactate, as well as modulation of monocarboxylate transporters (Harris et al, 2009). In our experiments, we observed increases in the $\mathrm{NAD}^{+} /$ $\mathrm{NADH}$ ratio and in $\mathrm{NAD}^{+}$in DCA-treated HT29 and HCT116 Bax-ko cell lines, which are consistent with the observed drop in $k_{\mathrm{PL}}$.

The observed increase in $\mathrm{NAD}^{+} / \mathrm{NADH}$ ratio following DCA treatment in our experiments is consistent with enhanced mitochondrial complex 1 activity leading to increased oxidation of NADH generated during glycolysis and the TCA cycle (Santidrian et al, 2013). The reduction in the Warburg effect during DCA-induced autophagy and PDK inhibition by DCA treatment could result in more pyruvate being diverted to the TCA cycle and a reduction in lactate excretion. Enhanced TCA cycle activity during autophagy may also lead to less reliance on aerobic glycolysis in autophagic cells with cellular homeostasis maintained by utilising autophagic degradation products to fuel cell metabolism (Rabinowitz and White, 2010). This is consistent with the $\mathrm{NAD}^{+} / \mathrm{NADH}$ ratio returning to control levels following recovery from DCA-induced autophagy in HCT116 Bax-ko cells. Our data are consistent with the known inverse relationship between lactate/ pyruvate ratios and $\mathrm{NAD}^{+} / \mathrm{NADH}$ ratios (Williamson et al, 1967; Christensen et al, 2014). Previous studies have shown that the $k_{\mathrm{PL}}$ rate constant has a strong linear correlation with lactate/pyruvate ratios (Witney et al, 2011; Hill et al, 2013b), and therefore a reduction in $k_{\mathrm{PL}}$ would be consistent with a decreased lactate/ pyruvate ratio and an increased $\mathrm{NAD}^{+} / \mathrm{NADH}$ ratio. Previously, we have also demonstrated a significant reduction in $k_{\mathrm{PL}}$ and an associated increase in $\mathrm{NAD}^{+} / \mathrm{NADH}$ ratio in autophagic cells in which autophagy had been induced by $24 \mathrm{~h}$ of PI103 treatment ( $k_{\mathrm{PL}}$ reduced to about $40-50 \%$ of control; Lin et al, 2014).
The magnitude of these changes is similar to the changes that we observed in DCA-treated HCT116 Bax-ko cells without the addition of DCA to the final cell suspensions.

The mean decreases in $k_{\mathrm{PL}}$ in DCA-treated HCT116 Bax-ko cells were greater (68\%) with DCA added to the final cell suspension mixture compared with $44 \%$ without DCA added to the suspension media, indicating that the combined effect of PDK inhibition and/or DCA-induced autophagy is about $44 \%$ and that the competitive inhibition of MCT-1 contributes an additional decrease in $k_{\mathrm{PL}}$ of about $24 \%$. This difference in the measured rates suggests that high concentrations of DCA can competitively inhibit the MCT-1 transporter. This would elicit a further additive effect, by slowing pyruvate entry into the cell and cause a further drop in $k_{\mathrm{PL}}$ in DCA-treated cells. Interestingly, both MCT-1 expression and activity of LDH were increased in DCA-treated cells, in contrast to the observed drop in $k_{\mathrm{PL}}$, and these changes suggest that the cells may be compensating for the combined effects of PDK and MCT-1 inhibition due to DCA treatment by upregulating MCT1 expression and LDH activity.

We have also examined the longitudinal effect on the measured $k_{\mathrm{PL}}$ in DCA-treated cancer cells undergoing autophagy and during their subsequent cellular recovery. The apparent rate constant $k_{\mathrm{PL}}$ was higher than control in the group that had recovered from DCA treatment and was associated with recovery of cell numbers to higher than control, and with a sustained increased MCT-1 expression and concentration of NADH, which would enable increased influx of pyruvate into the cell and increased turnover of hyperpolarised substrates in the cytosol. Total lactate excretion in cells recovering from DCA-induced autophagy returned to or above the level of 24 -h vehicle-treated controls, indicating that the cells had also recovered from the metabolic effects of DCA-induced autophagy. Similar cellular and metabolic changes were also observed in HCT116 Bax-ko cells recovered from PI103-induced or amino acid and serum deprivation-induced autophagy (Lin et al, 2014). Taken together, our data demonstrate that DCA-induced autophagy was reversible in our experiments.

DCA is currently in clinical trial (http://clinicaltrials.gov/show/ NCT01111097; Michelakis et al, 2010). Our study showed that DCA can induce autophagy in cancer cells and tumours and that this effect is independent of the cells' ability to undergo apoptosis. Our findings may have important implications for the use of DCA as a single anti-cancer agent, as the induction of autophagy by DCA could potentially be experienced by patients in the clinic. Treatment outcomes will be very different in tumours that are undergoing apoptosis $v s$ autophagy, as cells may recover from autophagy, thus prolonging their survival in hostile environments, aiding recovery once the stress is removed and promoting resistance to cancer treatment.

In conclusion, we found that DCA treatment increased ROS production, inhibited the mTOR pathway and induced autophagy in prostate and colorectal cancer cells and xenografts. Further studies are required to examine whether the increased ROS production and/or mTOR inhibition contribute to DCA-induced autophagy. Reduced $k_{\mathrm{PL}}$ and lactate excretion were seen in DCAtreated cells and xenografts, and this may be due to the mechanism of drug action of DCA (PDK and MCT-1 inhibition) and/or the autophagic process. Further studies are required to determine how DCA induces changes in molecular signalling pathways and whether these changes are caused by the alterations in cellular metabolism (downstream of PDK inhibition) or vice versa. Increased $k_{\mathrm{PL}}$ and lactate excretion recovered on cessation of treatment indicating that these processes are reversible, which could provide a potential marker of resistance to treatment. The use of hyperpolarised $\left[1-{ }^{13} \mathrm{C}\right]$ pyruvate and ${ }^{13} \mathrm{C}$-MRS may provide a useful method to monitor the effect of DCA on cancer cells and tumours, non-invasively. 


\section{ACKNOWLEDGEMENTS}

We acknowledge the support received from the CRUK and EPSRC Cancer Imaging Centre in association with the MRC and Department of Health (England) grant C1060/A10334, CRUK grant C1060/A16464, also NHS funding to the NIHR Biomedical Research Centre, Chang Gung Medical Foundation (Taiwan) grant CMRPG370441 and MRC-funded studentship (MRC119X). MOL is an NIHR Senior Investigator. We thank Alice Warley at the Kings College London Centre for Ultrastructural Imaging (CUI) for providing facilities for electron microscopy.

\section{REFERENCES}

Alexander A, Cai SL, Kim J, Nanez A, Sahin M, MacLean KH, Inoki K, Guan KL, Shen J, Person MD, Kusewitt D, Mills GB, Kastan MB, Walker CL (2010) ATM signals to TSC2 in the cytoplasm to regulate mTORC1 in response to ROS. Proc Natl Acad Sci USA 107(9): 4153-4158.

Ayyanathan K, Kesaraju S, Dawson-Scully K, Weissbach H (2012) Combination of sulindac and dichloroacetate kills cancer cells via oxidative damage. PLoS One 7(7): e39949.

Board M, Humm S, Newsholme EA (1990) Maximum activities of key enzymes of glycolysis, glutaminolysis, pentose phosphate pathway and tricarboxylic acid cycle in normal, neoplastic and suppressed cells. Biochem J 265(2): 503-509.

Bonnet S, Archer SL, Allalunis-Turner J, Haromy A, Beaulieu C, Thompson R, Lee CT, Lopaschuk GD, Puttagunta L, Harry G, Hashimoto K, Porter CJ, Andrade MA, Thebaud B, Michelakis ED (2007) A mitochondria-K+ channel axis is suppressed in cancer and its normalization promotes apoptosis and inhibits cancer growth. Cancer Cell 11(1): 37-51.

Cao W, Yacoub S, Shiverick KT, Namiki K, Sakai Y, Porvasnik S, Urbanek C, Rosser CJ (2008) Dichloroacetate (DCA) sensitizes both wild-type and over expressing $\mathrm{Bcl}-2$ prostate cancer cells in vitro to radiation. Prostate 68(11): 1223-1231.

Chen Y, Azad MB, Gibson SB (2009) Superoxide is the major reactive oxygen species regulating autophagy. Cell Death Differ 16(7): 1040-1052.

Chen Y, Gibson SB (2008) Is mitochondrial generation of reactive oxygen species a trigger for autophagy? Autophagy 4(2): 246-248.

Christensen CE, Karlsson M, Winther JR, Jensen PR, Lerche MH (2014) Non invasive in-cell determination of free cytosolic [NAD + ]/[NADH] ratios using hyperpolarized glucose show large variations in metabolic phenotypes. J Biol Chem 289(4): 2344-2352.

Chung YL, Griffiths JR (2007) Using metabolomics to monitor anticancer drugs. Ernst Schering Found Symp Proc 4: 55-78.

Chung YL, Griffiths JR (2011) Metabolomic Studies on Cancer and on Anticancer Drugs by NMR Ex Vivo in Encyclopedia of Magnetic Resonance, Harris RK, Wasylishen RE (eds). John Wiley: Chichester; doi:10.1002/ 9780470034590.emrstm1093.

Chung YL, Troy H, Banerii U, Jackson LE, Walton MI, Stubbs M, Griffiths JR, Judson IR, Leach MO, Workman P, Ronen SM (2003) Magnetic resonance spectroscopic pharmacodynamic markers of the heat shock protein 90 inhibitor 17-allylamino,17-demethoxygeldanamycin (17AAG) in human colon cancer models. J Natl Cancer Inst 95(21): 1624-1633.

Day SE, Kettunen MI, Gallagher FA, Hu DE, Lerche M, Wolber J, Golman K, Ardenkjaer-Larsen JH, Brindle KM (2007) Detecting tumor response to treatment using hyperpolarized ${ }^{13} \mathrm{C}$ magnetic resonance imaging and spectroscopy. Nat Med 13(11): 1382-1387.

Fiebiger W, Olszewski U, Ulsperger E, Geissler K, Hamilton G (2011) In vitro cytotoxicity of novel platinum-based drugs and dichloroacetate against lung carcinoid cell lines. Clin Transl Oncol 13(1): 43-49.

Geisler S, Holmstrom KM, Skujat D, Fiesel FC, Rothfuss OC, Kahle PJ, Springer W (2010) PINK1/Parkin-mediated mitophagy is dependent on VDAC1 and p62/SQSTM1. Nat Cell Biol 12(2): 119-131.

Golman K, in't Zandt R, Thaning M (2006a) Real-time metabolic imaging. Proc Natl Acad Sci USA 103(30): 11270-11275.

Golman K, Zandt RI, Lerche M, Pehrson R, Ardenkjaer-Larsen JH (2006b) Metabolic imaging by hyperpolarized ${ }^{13} \mathrm{C}$ magnetic resonance imaging for in vivo tumor diagnosis. Cancer Res 66(22): 10855-10860.
Han J, Hou W, Goldstein LA, Lu C, Stolz DB, Yin XM, Rabinowich H (2008) Involvement of protective autophagy in TRAIL resistance of apoptosisdefective tumor cells. J Biol Chem 283(28): 19665-19677.

Harris T, Eliyahu G, Frydman L, Degani H (2009) Kinetics of hyperpolarized ${ }^{13} \mathrm{C}_{1}$-pyruvate transport and metabolism in living human breast cancer cells. Proc Natl Acad Sci USA 106(43): 18131-18136.

Hill DK, Jamin Y, Orton MR, Tardif N, Parkes HG, Robinson SP, Leach MO, Chung YL, Eykyn TR (2013a) ${ }^{1} \mathrm{H}$-NMR and hyperpolarized ${ }^{13} \mathrm{C}-\mathrm{NMR}$ assays of pyruvate-lactate exhange: a comparative study. NMR Biomed 26(10): 1321-1325.

Hill DK, Orton MR, Mariotti E, Boult JKR, Panek R, Jafar M, Parkes HG, Jamin Y, Falck Miniotis M, Al-Saffar NMS, Beloueche-Babari M, Robinson SP, Leach MO, Chung YL, Eykyn TR (2013b) Model free approach to kinetic analysis of real-time hyperpolarized ${ }^{13} \mathrm{C}$ magnetic resonance spectroscopy data. PLoS One 8: e71996.

Jung CH, Ro SH, Cao J, Otto NM, Kim DH (2010) mTOR regulation of autophagy. FEBS Lett 584(7): 1287-1295.

Kroemer G, Marino G, Levine B (2010) Autophagy and the integrated stress response. Mol Cell 40(2): 280-293.

Kumar A, Kant S, Singh SM (2012) Novel molecular mechanisms of antitumor action of dichloroacetate against $\mathrm{T}$ cell lymphoma: Implication of altered glucose metabolism, $\mathrm{pH}$ homeostasis and cell survival regulation. Chem -Biol Interact 199(1): 29-37.

Kumar K, Wigfield S, Gee HE, Devlin CM, Singleton D, Li JL, Buffa F, Huffman M, Sinn AL, Silver J, Turley H, Leek R, Harris AL, Ivan M (2013) Dichloroacetate reverses the hypoxic adaptation to bevacizumab and enhances its antitumor effects in mouse xenografts. J Mol Med 91(6): 749-758.

Lin G, Andrejeva G, Wong Te Fong A-C, Hill DK, Orton MR, Parkes HG, Dow D-M, Robinson SP, Leach MO, Eykyn TR, Chung Y-L (2014) Reduced Warburg effect in cancer cells undergoing autophagy: steady- state ${ }^{1} \mathrm{H}$-MRS and real-time hyperpolarized ${ }^{13} \mathrm{C}$-MRS studies. PLoS One 9(3): e92645.

Liu L, Wise DR, Diehl JA, Simon MC (2008) Hypoxic reactive oxygen species regulate the integrated stress response and cell survival. J Biol Chem 283(45): 31153-31162.

Madhok BM, Yeluri S, Perry SL, Hughes TA, Jayne DG (2010) Dichloroacetate indcues apoptosis and cell-cycle arrest in colorectal cancer cells. BJC 102(12): 1746-1752.

Michelakis ED, Sutendra G, Dromparis P, Webster L, Haromy A, Niven E, Maguire C, Gammer TL, Mackey JR, Fulton D, Abdulkarim B, McMurtry MS, Petruk KC (2010) Metabolic modulation of glioblastoma with dichloroacetate. Sci Transl Med 2(31): 31ra34.

Narendra DP, Jin SM, Tanaka A, Suen DF, Gautier CA, Shen J, Cookson MR, Youle RJ (2010) PINK1 is selectively stabilized on impaired mitochondria to activate Parkin. PLoS Biol 8(1): e1000298.

Park JM, Recht LD, Recht, Josan S, Merchant M, Jang T, Yen Y-F, Hurd RE, Daniel M, Spielman DM, Mayer D (2013) Metabolic response of glioma to dichloroacetate measured in vivo by hyperpolarized ${ }^{13} \mathrm{C}$ magnetic resonance spectroscopic imaging. Neuro-oncol 15(4): 433-441.

Rabinowitz JD, White E (2010) Autophagy and metabolism. Science 330: 1344-1348.

Rzymski T, Milani M, Singleton DC, Harris AL (2009) Role of ATF4 in regulation of autophagy and resistance to drugs and hypoxia. Cell Cycle 8(23): 3838-3847.

Sanchez WY, McGee SL, Connor T, Mottram B, Wilkinson A, Whitehead JP, Vuckovic S, Catley L (2013) Dichloroacetate inhibits aerobic glycolysis in multiple myeloma cells and increases sensitivity to bortezomib. $\mathrm{Br} \mathrm{J}$ Cancer 108(8): 1624-1633.

Santidrian AF, Matsuno-Yagi A, Ritland M, Ritland M, Seo BB, LeBoeuf SE, Gay LJ, Yagi T, Felding-Habermann B (2013) Mitochondrial complex I activity and NAD $+/ \mathrm{NADH}$ balance regulate breast cancer progression. $J$ Clin Invest 123(3): 1068-1081.

Scherz-Shouval R, Shvets E, Fass E, Shorer H, Gil L, Elazar Z (2007) Reactive oxygen species are essential for autophagy and specifically regulate the activity of Atg4. Embo J 26(7): 1749-1760.

Seth P, Grant A, Tang J, Vinogradov E, Wang X, Lenkinski R, Sukhatme VP (2011) On-target inhibition of tumor fermentative glycolysis as visualized by hyperpolarized pyruvate. Neoplasia 13(1): 60-71.

Shen YC, Ou DL, Hsu C, Lin KL, Chang CY, Lin CY, Liu SH, Cheng AL (2013) Activating oxidative phosphorylation by a pyruvate dehydrogenase kinase inhibitor overcomes sorafenib resistance of hepatocellular carcinoma. Br J Cancer 108(1): 72-81. 
Sitter B, Sonnewald U, Spraul M, Fjosne HE, Gribbestad IS (2002) Highresolution magic angle spinning MRS of breast cancer tissue. NMR Biomed 15(5): 327-337.

Sun RC, Board PG, Blackburn AC (2011) Targeting metabolism with arsenic trioxide and dichloroacetate in breast cancer cells. Mol Cancer 10: 142.

Sun RC, Fadia M, Dahlstrom JE, Parish CR, Board PG, Blackburn AC (2010) Reversal of the glycolytic phenotype by dichloroacetate inhibits metastatic breast cancer cell growth in vitro and in vivo. Breast Cancer Res Treat 120(1): 253-260.

Sun W, Zhou S, Chang SS, McFate T, Verma A, Califano JA (2009) Mitochondrial mutations contribute to HIFlalpha accumulation via increased reactive oxygen species and up-regulated pyruvate dehydrogenease kinase 2 in head and neck squamous cell carcinoma. Clin Cancer Res 15(2): 476-484.

Tong J, Xie G, He J, Li J, Pan F, Liang H (2011) Synergistic antitumor effect of dichloroacetate in combination with 5-fluorouracil in colorectal cancer J Biomed Biotechnol 2011: 740564.

Tyagi RK, Azrad A, Degani H, Salomon Y (1996) Simultaneous extraction of cellular lipids and water-soluble metabolites: evaluation by NMR spectroscopy. Magn Reson Med 35(2): 194-200.

Ward CS, Venkatesh HS, Chaumeil MM, Brandes AH, Vancriekinge M, Dafni H, Sukumar S, Nelson SJ, Vigneron DB, Kurhanewicz J, James CD, Haas-Kogan DA, Ronen SM (2010) Noninvasive detection of target modulation following phosphatidylinositol 3-kinase inhibition using hyperpolarized ${ }^{13} \mathrm{C}$ magnetic resonance spectroscopy. Cancer Res 70(4): 1296-1305.
Williamson DH, Lund P, Krebs HA (1967) The redox state of free nicotinamide-adenine dinucleotide in the cytoplasm and mitochondria of rat liver. Biochem J 103(2): 514-527.

Witney TH, Kettunen MI, Brindle KM (2011) Kinetic modeling of hyperpolarized $13 \mathrm{C}$ label exchange between pyruvate and lactate in tumor cells. J Biol Chem 286(28): 24572-24580.

Wong CH, Iskandar KB, Yadav SK, Hirpara JL, Loh T, Pervaiz S (2010) Simultaneous induction of non-canonical autophagy and apoptosis in cancer cells by ROS-dependent ERK and JNK activation. PLoS One 5(4): e9996.

Workman P, Aboagye EO, Balkwill F, Balmain A, Bruder G, Chaplin DJ, Double JA, Everitt J, Farningham DA, Glennie MJ, Kelland LR, Robinson V, Stratford IJ, Tozer GM, Watson S, Wedge SR, Eccles SA. Committee of the National Cancer Research Institute (2010) Guidelines for the welfare and use of animals in cancer research. Br J Cancer 102(11): 1555-1577.

Zhang L, Yu J, Park BH, Kinzler KW, Vogelstein B (2000) Role of BAX in the apoptotic response to anticancer agents. Science 290(5493): 989-992.

(c) (1) (2) (2) This work is licensed under the Creative Commons BY Ac SA Attribution-NonCommercial-Share Alike 3.0 Unported License. To view a copy of this license, visit http://creativecommons. org/licenses/by-nc-sa/3.0/ 